\title{
VARIABILITY OF CINNAMOMUM (LAURACEAE) LEAF ARCHITECTURE IN RELATION TO CLIMATIC AND HISTORICAL CONSTRAINTS: IMPLICATIONS FOR PALEOCLIMATIC STUDIES
}

\author{
Mélanie Tanrattana, ${ }^{1, *}$ Jérémie Bardin, ${ }^{2, *}$ Anaïs Boura, ${ }^{3, *}$ Gwenaëlle Saulnier, ${ }^{4, *}$ and Dario De Franceschi ${ }^{5, *}$ \\ *UMR 7207, Centre de Recherche en Paléontologie-Paris Centre National de la Recherche Scientifique, Muséum National \\ d'Histoire Naturelle, Sorbonne Université, CP38, 8 rue Buffon, 75231 Paris Cedex 05, France
}

Editor: Isabel Sanmartín

Premise of research. Fossil leaves are commonly used as proxies for continental paleoclimate reconstruction. In particular, temperature and precipitation variables are derived from taxon-free methods using only fossil leaf morphology. Although there is a general relationship between leaf form and climate at a global scale, possible differences between and within angiosperm families remain little explored.

Methodology. In this article, we analyzed the influence of phylogenetic relatedness and climate on leaf architecture in 30 species of Cinnamomum (Lauraceae). Nineteen morphological features were selected and documented on the basis of digitized herbarium specimens. Repeatability was measured for all traits. Phylogenetic signal was measured using Blomberg's $K$. The relationship between morphological variables and climatic variables was investigated using univariate and multivariate statistical approaches.

Pivotal results. Our analysis revealed that phylogenetic signal was mainly observed in traits linked to the venation pattern. Size- and shape-related variables are more influenced by climatic parameters than by historical constraints. Cinnamomum leaf morphology is significantly correlated with mean annual temperature and temperature seasonality.

Conclusions. Shape and size are representative of convergent temperature-related characters in this genus. Our analysis validates the use of this genus for taxon-free paleoclimatic reconstruction methods relying on such data. The absence of phylogenetic signal in size- and shape-related traits contrasts with earlier studies on distantly related taxa and confirms that historical constraint on leaf morphology is variable among families.

Keywords: leaf morphometrics, climate, phylogeny, herbarium.

Online enhancements: supplemental tables.

\section{Introduction}

Numerous investigations of modern floras have demonstrated a relationship between leaf form and environment. In particular, the influence of climate on leaf morphology has been widely studied for more than a century (Bailey and Sinnott 1915, 1916; Dolph and Dilcher 1980a; Wolfe 1993, 1995; Wilf et al. 1998; Gregory-Wodzicki 2000; Huff et al. 2003; Greenwood et al. 2004; Traiser et al. 2005; Royer et al. 2008; Burnham and Tonkovich 2011; Peppe et al. 2011; Teodoridis et al. 2011; Yang et al. 2011; Royer 2012; Uhl 2014; Li et al. 2016a; Wright et al. 2017).

\footnotetext{
1 Author for correspondence; email: melanie.tanrattana@edu.mnhn.fr.

2 Email: jeremie.bardin@upmc.fr.

3 Email: anais.boura@upmc.fr.

${ }^{4}$ Email: gwenaelle.saulnier@edu.mnhn.fr.

5 Email: dario.de-franceschi@mnhn.fr.
}

Manuscript received February 2019; revised manuscript received August 2019; electronically published March 31, 2020.
Notable relationships include the proportions of entire-margined leaves and mean annual temperature (MAT; Bailey and Sinnott 1915; Wolfe 1995), leaf area and mean annual precipitation (MAP; Wolfe 1993; Wilf et al. 1998), and leaf apical shape and atmospheric humidity (Wolfe 1993; Farji-Brener et al. 2002).

Fossil leaves are abundant in the fossil record and hence are suitable proxies for terrestrial climate reconstruction. Fossil leaf assemblages have consistently been used to deduce paleoclimate (Wolfe 1995; Wilf et al. 1998; Huff et al. 2003; Su et al. 2010; Yang et al. 2011; Li et al. 2016a). Among these approaches, one relies on bulk leaf physiognomies at a given fossil locality to assess paleoclimatic conditions using form-climate relationships as documented in extant floras (Wolfe 1995; Huff et al. 2003; Yang et al. 2011; Li et al. 2016a). This taxon-free approach, including methods such as climate leaf analysis multivariate program (CLAMP), digital leaf analysis, or, most recently, climate leaf analysis with neural networks, relies on the core assumption that similar climatic constraints will lead to morphological convergence among and within families of woody dicotyledon angiosperms (Huff et al. 2003; Yang et al. 2015; Li et al. 2016a). 
Although physiognomic methods have been used for several decades and have provided inferences consistent with other proxies (Herman and Spicer 1997; Kennedy et al. 2002), some aspects are not yet resolved. For instance, some studies have shown that biogeography had an influence on leaf form-climate relationships (Gregory-Wodzicki 2000; Kowalski 2002; Traiser et al. 2005; Hinojosa et al. 2011). Moreover, species do not always show the same morphological response to climatic variations (Royer et al. 2008). Most recently, another matter of concern has been the global influence of the phylogenetic signal on leaf shape (Little et al. 2010; Burnham and Tonkovich 2011; Hinojosa et al. 2011; Yang et al. 2015; Li et al. 2016b; GladeVargas et al. 2018), suggesting that some shared leaf traits are due to phylogenetic inheritance rather than to convergence in certain families. This aspect challenges our traditional view on leaf shape-climate relationship and calls for thoroughly assessing the impact of phylogenetic signal on paleoclimatic interpretation (Burnham and Tonkovich 2011; Peppe et al. 2018).

A way to tackle these issues is to investigate in detail the relationship among leaf morphology, phylogenetic signal, and climate in families or genera with an abundant fossil record that have a high probability of being included in paleoclimatic reconstruction. Only a few studies have analyzed morphological variability in relation to climate using a species-based or phylogenybased approach with implications for paleoclimatic reconstructions (Royer et al. 2008; Little et al. 2010; Royer 2012; Schmerler et al. 2012; Uhl 2014; Glade-Vargas et al. 2018).

The Lauraceae family, in particular the emblematic genus Cinnamomum, is of particular interest in this endeavor. First, this genus (ca. 350 species) is characterized by a wide geographic distribution and varied ecological preferences. It occurs in South America, Asia, and Australia and can be found in lowland evergreen broad-leaved forests, in montane forests (Schnell 1987; Lorea-Hernández 1996), and up to $2000 \mathrm{~m}$, as in the Himalayas. Some species are important components of cloud forests in South America (Lorea-Hernández 1996) and Araucaria forests in southern Brazil (Schnell 1987). Second, Cinnamomum displays varied leaf morphologies, including elliptic to obovate forms; triplinerved and pinninerved venation patterns; and acute, round, or attenuate apexes (Lorea-Hernández 1996; Ho and Hung 2011; Wuu-Kuang 2011). To our knowledge, relationships between these traits and various ecological and climatic contexts have never been tested, especially at a large geographic scale and including species from diverse regions. Finally, an essential aspect is the putative abundance of the genus in the fossil record from the Paleocene to the Miocene in a wide geographic range, mainly on the basis of the occurrence of triplinerved leaves (Laurent 1912; Holden 1982; Taylor 1988; Conran and Christophel 1998; Khan and Bera 2014; Shi et al. 2014). In fact, this type of leaf is not exclusive to Cinnamomum and is common among the extant Lauraceae family. Nevertheless, extant Cinnamomum broadly covers the morphological diversity of these triplinerved leaves, which are commonly encountered in the Cenozoic leaf record. Therefore, the understanding of climate versus phylogenetic signal in extant triplinerved leaves of Lauraceae could provide useful insights into paleoclimatic interpretations using traditional methods such as CLAMP.

In the following, we investigate leaf form-climate relationships at the intrageneric scale using the digitized herbarium collection of the Muséum National d'Histoire Naturelle in Paris (Le Bras et al. 2017). The aims of this study are (1) to disentangle the influence of climate and phylogenetic history on selected Cinnamomum leaf traits using a species-based approach and (2) to discuss the relevance of Cinnamomum leaf traits for paleoclimatic studies.

\section{Material and Methods}

\section{Phylogenetic Framework}

Phylogenetic analyses have shown that the genus Cinnamomum, as traditionally understood, is polyphyletic and is part of the Cinnamomum group, which also includes some species previously assigned to the genera Mocinnodaphne, Aiouea, and Ocotea (Chanderbali et al. 2001; Huang et al. 2016; Rohde et al. 2017). However, three well-supported clades were recently recovered by Huang et al. (2016). Two of them (clade 1 and clade 2) correspond to the Asiatic Cinnamomum (sections Cinnamomum and Camphora, which were previously recognized on the basis of morphology) and to Ocotea (a single species, nested in clade 2). The third one (clade 3 ) includes Neotropical Cinnamomum species and representatives of Aiouea and Mocinnodaphne.

A time-calibrated phylogeny adapted from Huang et al. (2016) and including these three clades was used as phylogenetic framework for our study. The initial phylogeny includes 76 species, covering nearly the entire geographic distribution of the group (Huang et al. 2016). Divergence times and branch lengths were estimated using a secondary calibration approach (for details on the analysis, see Huang et al. 2016).

The tree was pruned to represent the 25 Cinnamomum species present in the herbarium collections. Five Neotropical species from the phylogeny of Lorea-Hernández (1996) were added using Mesquite (Maddison and Maddison 2017). These 30 species include representatives of the three clades recovered by Huang et al. (2016) in various proportions. The least well represented is clade 1 , with only $23 \%$ of the species present in our sampling. Clade 2 and 3 species are represented at $40 \%$ and $60 \%$, respectively. Branch-length data for the Neotropical species were corrected manually on the basis of branch-length data available for Cinnamomum triplinerve (Ruiz \& Pav.) Kosterm. from Huang et al. (2016). We assumed that branch lengths were similar for all Neotropical taxa (polytomy), which might not be the case but was considered the more neutral hypothesis.

\section{Herbarium Material Sampling}

This study is based on digitized historical herbarium collections available on the ReColNat online database (http://explore .recolnat.org). Herbarium specimens of Cinnamomum were selected using the following criteria: (i) only species present in the phylogenetic framework were analyzed; (ii) specimens for which georeferenced data were not obtainable were discarded; (iii) herbarium sheets with only damaged and/or overlapping leaves were not retained; (iv) cultivated specimens were avoided; and (v) only mature leaves were studied, and herbarium sheets with only juvenile leaves were discarded. Maturity was assessed by leaf size and position on the branch; the leaves that were the largest and farthest from the branch tip were retained. Only specimens clearly matching all five criteria were included in the analysis.

We were able to retrieve 32 species from the Huang et al. (2016) and Lorea-Hernández (1996) phylogenies in the ReColNat 
database (976 specimens in total). After the "phylogenetic selection," 221 specimens were found to be well preserved, presenting at least one mature leaf, and geolocatable, meaning that climatic data could be retrieved for these specimens. This final selection represents the 30 species mentioned above and distributed in South America, Asia, and Africa (tables A1, A2; tables A1-A5 are available online).

\section{Morphometric Data}

Nineteen morphological features were selected and documented (fig. 1; table 1). We designed a method allowing a semiautomated measurement of leaves on a herbarium sheet, as follows. A single mature well-preserved leaf per herbarium sheet is manually segmented from the background using Adobe Photoshop CS6. Measuring all visible leaves on a herbarium specimen would be biased by the fact that most of them present both juvenile and mature leaves. We chose to measure only one leaf to avoid this intraindividual variability due mainly to ontogeny.

Length, width, area, perimeter, and petiole width were automatically measured using the morphometry software Free-D (Andrey and Maurin 2005), including the plug-in MorphoLeaf (Biot et al. 2016). Further measurements, including secondary vein length (SVL), angle between a secondary vein and the primary veins, and leaf apex and base angles, were manually measured with ImageJ (Schneider et al. 2012). Angle between a secondary vein and the primary veins is the angle from the insertion of the secondary vein to the pair of points on the perpendicular line at one-quarter of the same SVL (fig. 1). Apex and base angles were measured according to the Manual of Leaf Architecture (Ellis et al. 2009). Apex and base types and distance of secondary length insertion (basal or suprabasal) were observed and scored manually (fig. 1).

\section{Sampling Size}

Heterogeneity in sampling effort might be an issue in subsequent statistical analyses. First, variance of the error term is not constant for all values within a variable. Second, species with only one specimen available can be problematic because their genuine variance cannot be taken into account in analyses. To address these concerns, we first assessed the potential measurement error (in a statistical sense, a deviation of any kind that appears between an observed value and a true value; Garamszegi 2014) in our data by calculating the repeatability $(R)$ of each measured trait. $R$ is the proportion of the between-subject variance relative to the total variance (Sokal and Rohlf 1995):

$$
R=\frac{\sigma_{\text {between }}^{2}}{\sigma_{\text {between }}^{2}+\sigma_{\text {within }}^{2}},
$$

where $\sigma_{\text {between }}^{2}$ is between-species variance and $\sigma_{\text {within }}^{2}$ is withinspecies variance.

An $R$ value close to 1 means that a single individual will reflect the true species-specific value of a given trait in regard to other species values. A low $R$ value indicates that within-species variance might require some statistical treatment (Garamszegi 2014). Typically, the following threshold values are used to assess the level of repeatability: $R<0.2$ is associated with slight repeatability, $0.2<R<0.4$ with low repeatability, $0.4<R<0.7$
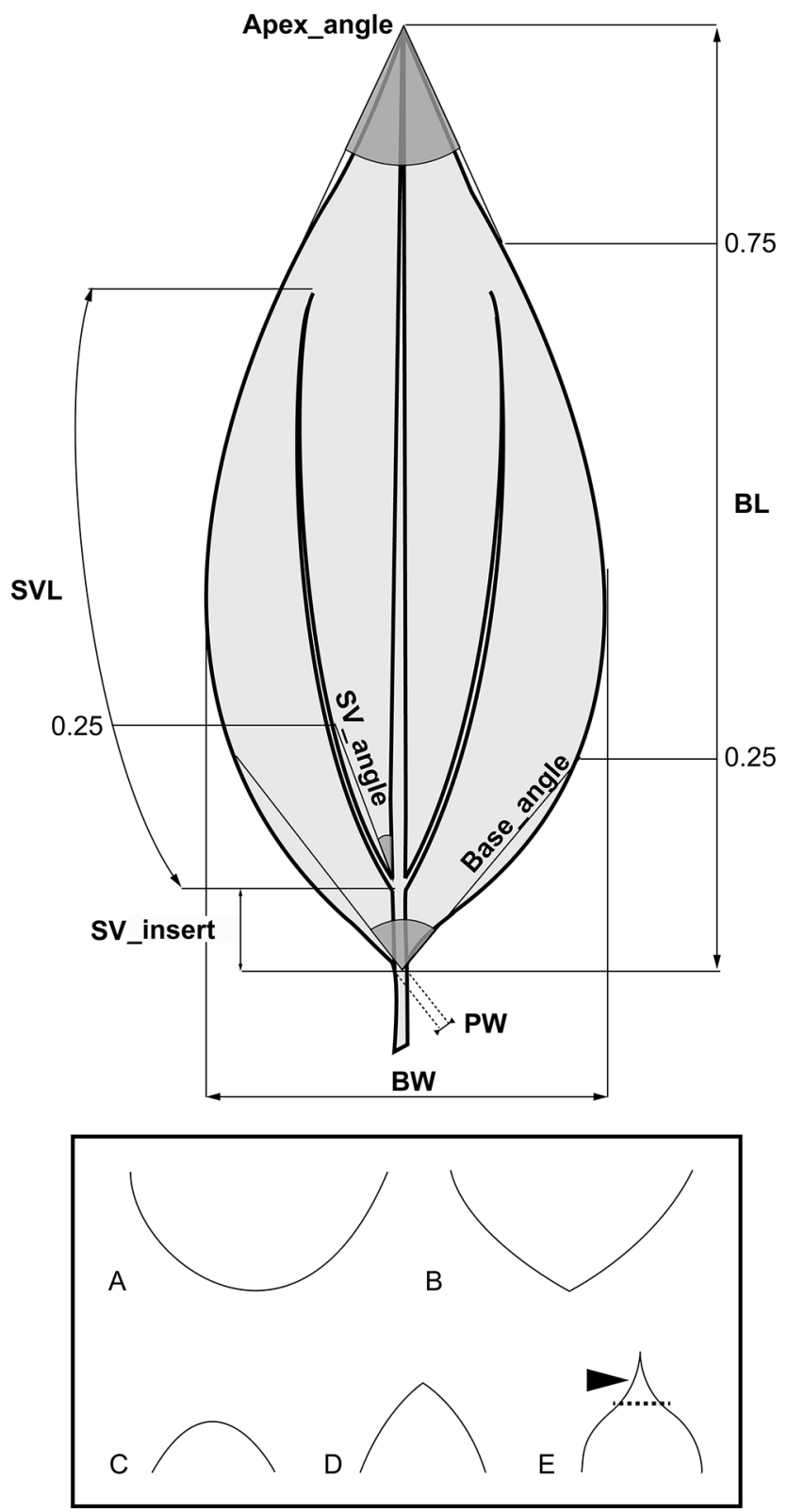

Fig. 1 Leaf traits measured in this study. $A, B$, Types of base. $A$, Round base. $B$, Acute base. $C-E$, Types of apex. $C$, Round apex. $D$, Acute apex. E, Attenuate apex. The arrowhead indicates the acumen. $\mathrm{BL}=$ blade length; $\mathrm{BW}=$ blade width; $\mathrm{PW}=$ petiole width; SV_angle $=$ secondary vein angle; SV_insert $=$ insertion of secondary vein; $S V L=$ secondary vein length.

with moderate repeatability, $0.7<R<0.9$ with high repeatability, and $R<0.9$ with very high repeatability (Harper 1994).

To account for nonconstant variance in the error term, we calculated a pooled variance (Ives et al. 2007; Hansen and Bartoszek 2012). The latter is calculated with the data of species represented by more than one specimen (i.e., $n>1$ ) and can be used to estimate a variance for species where $n=1$ (variance cannot be calculated). For each trait, the pooled variance is 


\section{Table 1}

Morphological Traits Measured on Cinnamomum Leaves

\begin{tabular}{ll}
\hline Abbreviation & \multicolumn{1}{c}{ Trait (unit) } \\
\hline BL & Lamina length $(\mathrm{cm})$ \\
BW & Lamina width $(\mathrm{cm})$ \\
LW_ratio & Lamina length-to-width ratio \\
BA & Lamina area $\left(\mathrm{cm}^{2}\right)$ \\
BP & Lamina perimeter $(\mathrm{cm})$ \\
PW & Petiole width $(\mathrm{cm})$ \\
Apex_angle & Measured angle from first quarter to the apex $\left(^{\circ}\right)$ \\
Base_angle & Measured angle from third quarter to the base $\left(^{\circ}\right)$ \\
AB_ratio & Ratio of apex_angle to base_angle \\
Apex_round & Both sides of the apex are convex (abundance) \\
Apex_acute & Both sides of the apex are straight (abundance) \\
Apex_attenuate & Both sides of the apex are concave (abundance) \\
Base_round & Both sides of the base are convex (abundance) \\
Base_acute & Both sides of the apex are straight or concave \\
& (abundance) \\
SV_insert & Suprabasal or basal (abundance) \\
Acumen_length & Length of the acumen (mm) \\
SVL & Length of the first pair of secondary veins (cm) \\
SV_angle & Angle between the main vein and the first secondary \\
SVL/BL & veins \\
\hline
\end{tabular}

calculated following Hansen and Bartoszek (2012) to account for the number of specimens per species, as follows:

$$
\bar{\sigma}^{2}=\frac{\sum_{i=1}^{N_{\text {species }}} \sigma_{\text {within }_{i}}^{2}\left(n_{i}-1\right)}{\sum_{i=1}^{N_{\text {species }}}\left(n_{i}-1\right)},
$$

where $\bar{\sigma}^{2}$ is the pooled variance, $n_{i}$ is the number of specimens in a considered species, and $N_{\text {species }}$ is the number of species where $n_{i}>1$.

Then, specific variance pondered by $n_{i}\left(\bar{\sigma}_{n_{i}}^{2}\right)$ is calculated as follows:

$$
\bar{\sigma}_{n_{i}}^{2}=\frac{\bar{\sigma}^{2}}{n_{i}} .
$$

Species with a single measurement are thus given a variance equal to the pooled variance. This estimation can be problematic if the true variances vary widely because of scaling effects (Garamszegi 2014). Since this study is conducted within a single genus, we make the assumption that this scaling effect is negligible. These estimated variances are then used as weights in the linear models.

\section{Climatic Data}

Missing geolocation data were acquired using the website Les Herbonautes (http://lesherbonautes.mnhn.fr). This citizen science project is a collaborative initiative to digitize herbarium sheet labels by manual transcription. Site description is used to estimate the site coordinates in a Google Maps application. For each site, several estimated coordinates are compared, and if the difference between them is less than $1 \mathrm{~min}$ ( $1.9 \mathrm{~km}$ at the equator), means are calculated and the references are validated. Otherwise, all the participants discuss them until approval.
Latitude and longitude of each specimen were compiled to obtain climatic data from the WorldClim database (Hijmans et al. 2005 ) using the raster function in $\mathrm{R}$ ( $\mathrm{R}$ Core Team 2017). The database comprises 19 bioclimatic variables (table A3): MAT, mean diurnal range of temperature, isothermality, temperature seasonality $\left(T_{\text {seasonality }}\right)$, maximum temperature of warmest month, minimum temperature of coldest month, temperature annual range $\left(T_{\text {range }}\right)$, mean temperature of wettest quarter, mean temperature of driest quarter, mean temperature of warmest quarter $\left(T_{\text {warmest_Q }}\right)$, mean temperature of coldest quarter, MAP, precipitation of wettest month, precipitation of driest month $\left(P_{\text {driest_M }}\right)$, precipitation seasonality $\left(P_{\text {seasonality }}\right)$, precipitation of wettest quarter, precipitation of driest quarter $\left(P_{\text {driest }}\right)$, precipitation of warmest quarter, and precipitation of coldest quarter.

\section{Statistical Analyses}

Phylogenetic signal is defined as the tendency of related species to resemble each other more than they resemble species drawn randomly from the tree (Münkemüller et al. 2012). This signal was estimated using Blomberg's $K$ (Blomberg et al. 2003). The latter is defined as the ratio between two other ratios, which are (1) the mean squared error of tip data divided by the mean squared error of data, calculated using a variance-covariance matrix derived from the phylogeny (observed), and (2) the same but calculated using data from a model under the assumption of Brownian motion of trait evolution (expected). Thus, a $K$ value lower than 1 indicates that closely related species resemble each other less than expected under the Brownian motion model of trait evolution. A $K$ value above 1 indicates that closely related species are more similar than predicted by the model. In other words, greater values of $K$ suggest a strong phylogenetic signal.

Statistical analyses were conducted using R. Repeatability was measured for all traits using the rpt function in the rptR package (Stoffel et al. 2017). Blomberg's $K$ for each morphological trait was calculated using the phylosig function included in the phytools package (Revell 2012). In order to investigate the relationship between morphological variables and climatic variables, we used simple linear regression and canonical correspondence analysis (CCA; Ter Braak 1986). Historically, this multivariate analysis was introduced to relate community composition to known environmental variation (Ter Braak 1986). CCA was successfully used to analyze the relationships between leaf morphology and climate (Wolfe 1993). We ran CCAs for both intraspecific data (tables A1, A2) and interspecific data (tables A4, A5).

\section{Results}

\section{Effect of Sampling Size}

$R$ values calculated for Cinnamomum traits are all greater than 0.2 and range from low to very high (table 3 ). Blade width and area, length-to-width ratio, apex and base angles, apex-tobase ratio, and secondary vein insertion and angle all show moderate repeatability, with $R$ between 0.4 and 0.7 . Blade length (BL), perimeter, rounded apex, and SVL show high repeatability, with $R$ between 0.7 and 0.9 . Acute base shows very high repeatability, with $R<0.9$. Petiole width, acute and attenuate apex, 
round base, and acumen length are associated with low repeatability $(0.2<R<0.4)$.

Nonweighted linear models show significant relationships between leaf morphology and both temperature and precipitation variables, but only temperature-related weighted models were still significant (table 3 ). Most $R^{2}$ values were lower in the weighted models. However, most of the traits with high repeatability still have a significant relationship with climatic variables, even in the weighted models.

\section{Phylogenetic Signal}

Significant, relatively high phylogenetic signal was observed in five morphological traits (table 2; fig. 2): (1) petiole width (fig. $2 A$ ) is particularly high in the clade including C. verum J. Presl, C. multiflorum (Roxb.) Wight, C. bejolghota (Buch.Ham.) Sweet, C. iners Reinw. ex Blume, C. javanicum Blume, and C. tonkinense (Lecomte) A.Chev.; (2) closely related species tend to have similar acumen lengths; (3), (4) SVL and SVL-to$\mathrm{BL}$ ratio (fig. $2 C, 2 D$ ) are lower in Neotropical species and among Asiatic species in clade $1 ;(5)$ the same dichotomy is ob-

Table 2

Blomberg's $K$ Results for Cinnamomum Morphological and Selected Climatic Variables

\begin{tabular}{lll}
\hline Variable & $K$ & $P$ \\
\hline MAT & $.56^{*}$ & .04 \\
$T_{\text {seasonality }}$ & .51 & .1 \\
$T_{\max }$ & .47 & .17 \\
$T_{\min }$ & .5 & .1 \\
MAP & $.64^{*}$ & .02 \\
$P_{\text {seasonality }}$ & .34 & .74 \\
BL & .55 & .06 \\
BW & .53 & .08 \\
LW_ratio & .62 & .12 \\
BA & .54 & .11 \\
BP & .55 & .08 \\
PW & $.76^{*}$ & .001 \\
Apex_angle & .5 & .14 \\
Base_angle & .55 & .07 \\
AB_ratio & .51 & .1 \\
Apex_round & .45 & .27 \\
Apex_acute & .51 & .1 \\
Apex_attenuate & .5 & .08 \\
Base_round & .36 & .66 \\
Base_acute & .35 & .67 \\
SV_insert & .35 & .69 \\
Acumen_length & $.6^{*}$ & .02 \\
SVL & $.67^{*}$ & .01 \\
SV_angle & $1.03^{*}$ & .004 \\
SVL/BL & $.71^{*}$ & .01 \\
\hline
\end{tabular}

Note. $\quad \mathrm{AB} \_$ratio $=$apex-to-base ratio; $\mathrm{BA}=$ blade area; $\mathrm{BL}=$ blade length; $\mathrm{BP}=$ blade perimeter; $\mathrm{BW}=$ blade width; $\mathrm{LW} \_$ratio = length-towidth ratio; $\mathrm{MAP}=$ mean annual precipitation; $\mathrm{MAT}=$ mean annual temperature; $P_{\text {seasonality }}=$ precipitation seasonality; $\mathrm{PW}=$ petiole width; SV_angle $=$ secondary vein angle; $S V \_$insert $=$secondary vein insertion; $S V L=$ secondary vein length; SVL/BL $=$ secondary vein length-to-blade length ratio; $T_{\max }=$ maximum temperature of the warmest month; $T_{\min }=$ minimum temperature of the coldest month; $T_{\text {seasonality }}=$ temperature seasonality.

$* P<0.05$. served for secondary vein angle, which is smaller in clade 2 (fig. 2B). Other traits bear no significant phylogenetic signal. Finally, significant phylogenetic signal was observed in both MAT and MAP data (table 2).

\section{Relationship between Leaf Physiognomy and Climatic Variables}

Length, width, length-to-width ratio, area, and perimeter are positively correlated with MAT and annual minimum temperature $\left(T_{\min }\right.$; fig. 3 ; table 3$)$. Length and perimeter are negatively correlated with $T_{\text {seasonality }}$ (fig. 3 ; table 3 ). Apex angle is negatively correlated with MAT and annual maximum temperature $\left(T_{\max }\right.$; table 3$)$. Finally, acute apex is more likely in warm climates and less likely in temperature-seasonal climates.

The CCA carried out at the intraspecific level (i.e., on the basis of values for each individual specimen; not illustrated) reveals that only $17 \%$ of the variance is explained by climate (ANOVA, $P<0.05$ ). The CCA carried out at the interspecific level (i.e., on the basis of mean values for each species; illustrated in fig. 4) shows that $78 \%$ of morphological variability is explained by climatic variables (ANOVA, $P<0.05$ ). The three first ordination axes explain $73 \%$ of the constrained variance (table 4 ).

The intraset correlation coefficients (correlation of environmental variables with the linear combination scores) reveal that the CCA 1 and CCA 2 ordination axes are most correlated with $T_{\text {min }}$, MAT, $T_{\text {range }}$, and $T_{\text {seasonality }}$ and $T_{\text {max }}, T_{\text {warmest_Q }}$, $P_{\text {driest_M }}$, and $P_{\text {driest_Q}}$, respectively (table 4 ). Most of the variation of Cinnamomum is therefore mainly linked to temperature and especially to $T_{\text {seasonality }}$. To a lesser extent, the ordination axes are also related to precipitation. Notably, $P_{\text {driest } M}$ and $P_{\text {seasonality }}$ show slight correlation with the two first ordination axes (table 4). To summarize, CCA1 is linked to $T_{\text {seasonality }}$ and MAT, with highly seasonal climate and colder MAT on the left part of figure 4 and more isothermal climates with higher MAT on the right side. To a lower degree, CCA2 is linked to $T_{\max }$ and $P_{\text {driest_Q }}$, the bottom part of figure 4 being representative of high precipitation during the dry period and lower $T_{\max }$.

Rounded apexes and bases are more likely to occur in seasonal climates with relatively low MATs. Attenuate and acute apexes are more likely to occur in climates with seasonal precipitation and in climates characterized by equable (and elevated) annual precipitations, respectively. Large leaf area is associated with high annual precipitation and MAT and equable climates.

\section{Discussion}

\section{Sampling Effort}

Our selection of species represents well the broad climatic range characterizing Cinnamomum (Schnell 1987; LoreaHernández 1996), with MATs ranging from $10.5^{\circ}$ to $26.6^{\circ} \mathrm{C}$, $T_{\text {max }}$ from $23.4^{\circ}$ to $34.7^{\circ} \mathrm{C}, T_{\text {min }}$ from $-5.35^{\circ}$ to $21.2^{\circ} \mathrm{C}$, and MAP from 636 to $4086 \mathrm{~mm}$.

Despite the heterogeneity of our sampling, only apex type was associated with a low repeatability (table 3 ). Therefore, sampling effort should be improved to obtain more reliable means. Repeatability was relatively high in the other leaf traits measured in this study (table 3 ), suggesting that the limited sampling within each species is well representative of the species and that 

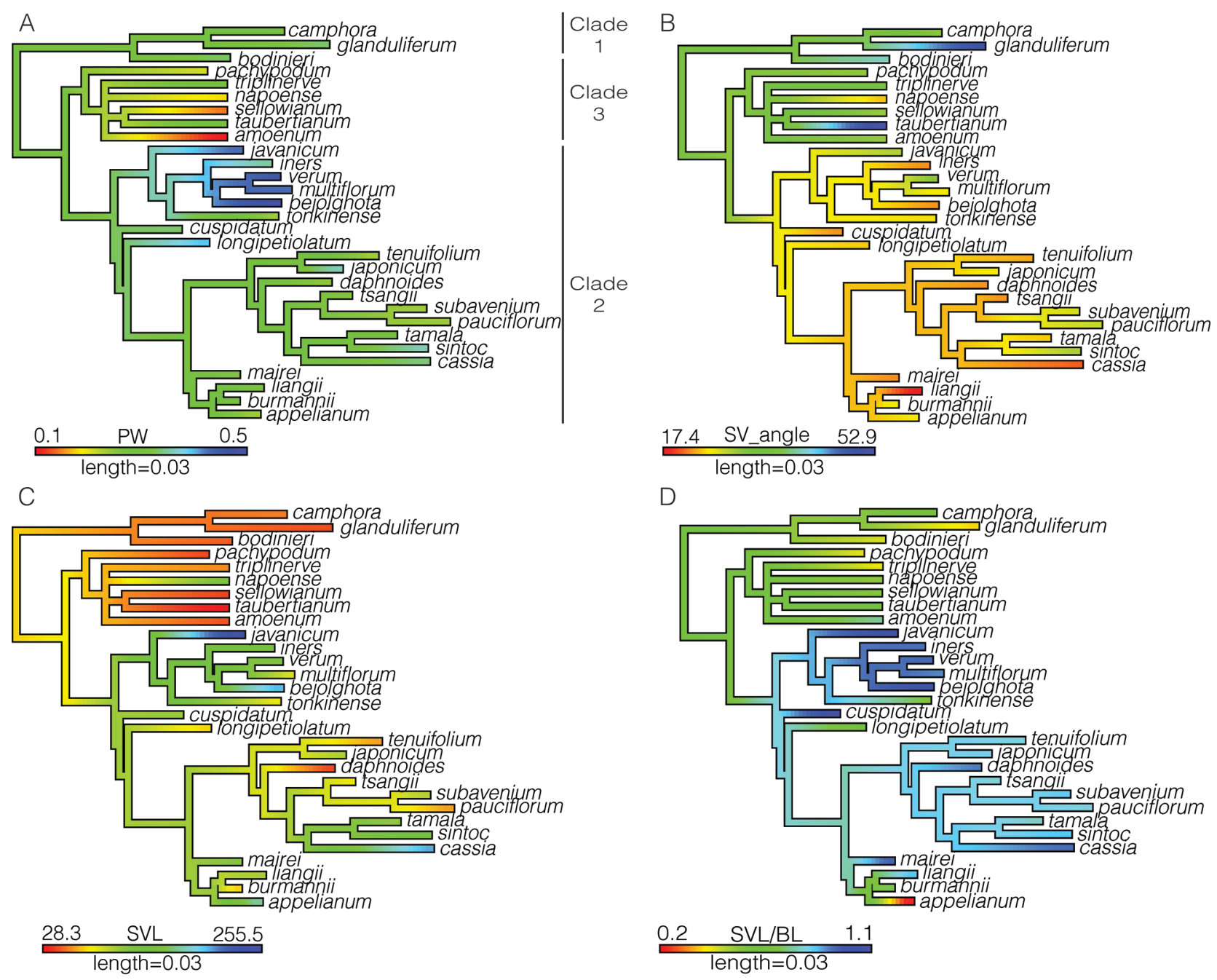

Fig. 2 Mapping of selected leaf traits displaying phylogenetic signal. A, Petiole width (PW). Scale bar is shown in centimeters. $B$, Secondary vein angle (SV_angle). Scale bar is shown in degrees. C, Secondary vein length (SVL). Scale bar is shown in millimeters. D, Secondary vein length-toblade length ratio (SVL/BL).

intraspecific variability is not an issue in our interspecific analyses (Garamszegi 2014).

Another issue is the limited sampling used in this study (30 species), which represents $\sim 10 \%$ of the genus's diversity. Although this sampling represents well the three clades recovered in the genus and its broad climatic range, phylogenetic representation should be improved in future studies, for example, by covering more species within each clade. Nevertheless, according to the objective of this study, it is most important to include various species with well-known phylogenetic position living in contrasting environmental conditions.

\section{Influence of Phylogenetic History on Cinnamomum Leaf Morphology}

Phylogenetic inheritance is an important driver of leaf form and has an influence on the relationship between leaf morphology and climate at a global scale (Little et al. 2010; Hinojosa et al. 2011; Li et al. 2016b; Glade-Vargas et al. 2018). Phylogenetic signal is particularly high in leaf margin traits, although significant but lower phylogenetic signal is also observed in shape and size traits (Little et al. 2010; Glade-Vargas et al. 2018).

Here, we tested the presence of phylogenetic signal at a lower taxonomical level in a homogeneously untoothed genus. In contrast to the Little et al. (2010) study, in this study phylogenetic signal was significantly high only for five leaf traits, mostly linked to venation pattern but not to size or shape (table 2). This result is in line with a previous study investigating the evolution of the relationship between leaf size and altitude that showed that leaf size was less influenced by phylogeny than by environmental factors (Milla and Reich 2011).

Phylogenetic signal is significant in traits related to venation pattern. This result suggests that secondary vein pattern could be useful for taxonomic studies in the genus and calls for further studies of phylogenetic signal in higher-order venation. One of these traits, SVL, often scales with leaf size as it develops during leaf expansion (Sack et al. 2012). In our study, as expected, BL shows no significant phylogenetic signal and is correlated with climatic parameters (tables 2,3 ). In contrast, SVL and SVL-to-BL ratio are similar for clades 1 and 3 , as opposed to clade 2 . This 

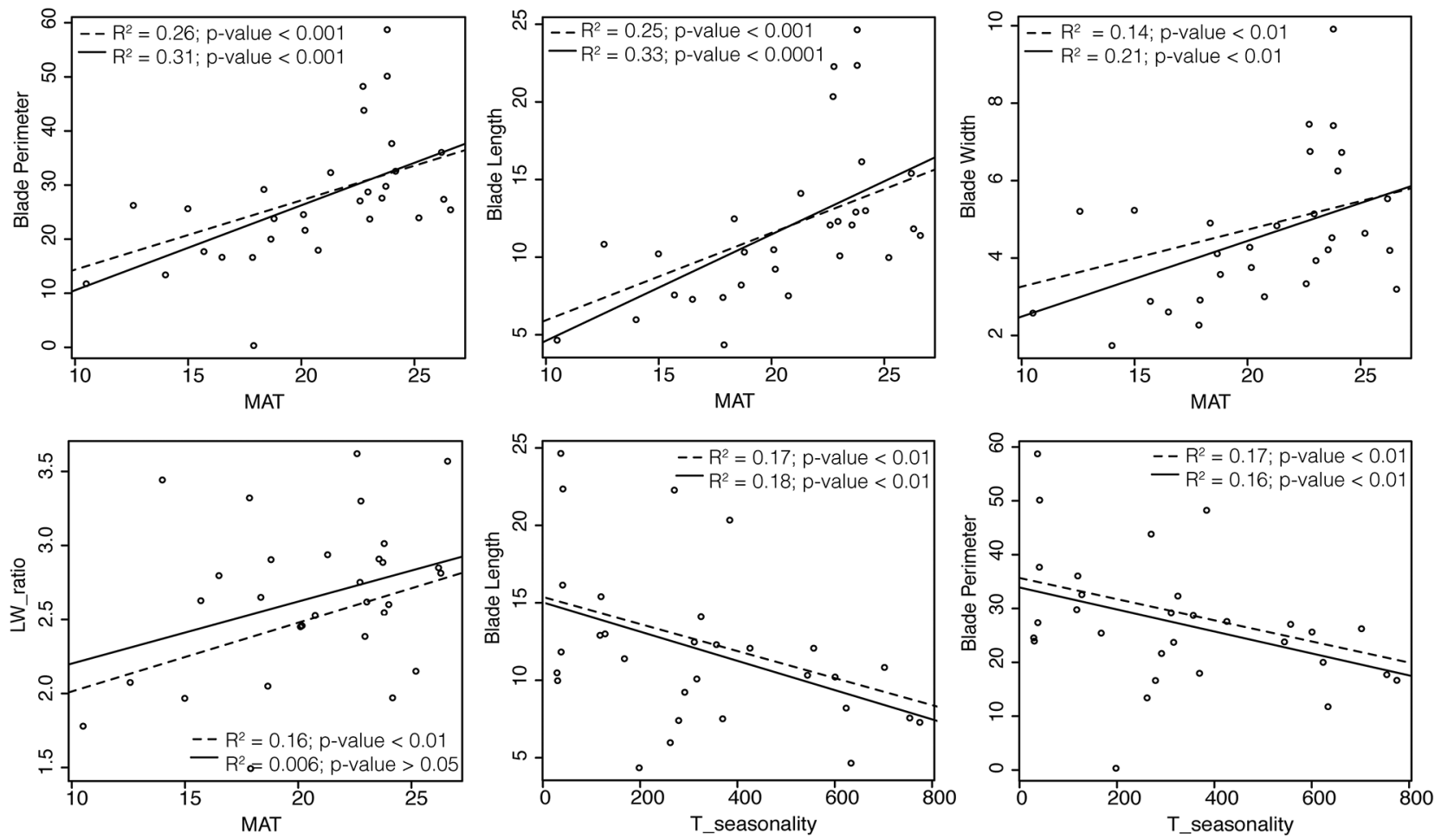

Fig. 3 Relationship between selected morphological traits of Cinnamomum and temperature variables. Dotted lines indicate weighted models, solid lines indicate nonweighted models. LW_ratio = length-to-width ratio; MAT = mean annual temperature; T_seasonality $=$ temperature seasonality.

suggests that BL is influenced by climate, while SVL-to-BL ratio is more conservative and is determined by phylogeny.

Finally, phylogenetic signal was also observed in MAT and MAP (table 2), suggesting that, when these variables are taken into account, closely related Cinnamomum species live under relatively similar climates. A relationship between size- and shaperelated traits and climate, particularly for temperature variables, is observed (table 3). Nevertheless, phylogenetic signal was not observed for these traits. This contradictory pattern can be explained by a convergence of morphology under similar climatic conditions for the different lineages. On the other hand, phylogenetic signal in climatic variables could imply phylogenetic niche conservatism ("the phenomenon that closely related species are more ecologically similar than might be expected solely as a BM evolution"; Losos 2008, p. 996) within lineages, although the relationship between phylogenetic similarity and ecological similarity should be more thoroughly tested to confirm this hypothesis (Losos 2008). In other words, sister species tend to share relatively similar ecologies (hence phylogenetic signal in climatic variables), while a morphological convergence occurs in distantly related species (thus, a relationship is observed between some morphological traits and climatic variables).

\section{Relationship between Cinnamomum Leaf Morphology and Climate}

As expected, Cinnamomum leaf size and shape traits correlate, although not strongly, with climatic conditions (table 3; figs. 3, 4). However, while nonweighted linear models show significant relationships between leaf morphology and both temperature and precipitation variables, only temperature-related weighted models were still significant and thus considered reliable (table 3). Concurrently, temperature-related variables show the strongest correlation coefficients in the CCA (table 4). The main results are (1) large leaves indicate a warm, equable climate, (2) BL and blade perimeter are negatively correlated with temperature seasonality, and (3) rounded apex and apex-to-base ratio are negatively correlated with MAT. These results are largely consistent with the multivariate analysis (fig. 4). Correlation between size and temperature in Cinnamomum is consistent with previous studies focusing on tropical leaves at the community level (Dolph and Dilcher 1980a, 1980b) and with worldscale studies investigating the relationships among size, climate, and ecophysiology (Moles et al. 2014; Wright et al. 2017). Large-leaved Cinnamomum species occur in both Asian and South American continents, suggesting that leaf size is a convergent climate-driven feature.

Variations in Cinnamomum leaf size are also indicative of temperature seasonality; that is, Cinnamomum leaves tend to have a smaller leaf area in seasonal climates. Some species with very specific morphologies are associated with specific climates. For instance, Cinnamomum growing in localities with high temperature seasonality and relatively low MAT $\left(<18^{\circ} \mathrm{C}\right)$, such as C. daphnoides Siebold \& Zucc. and C. taubertianum (Mez \& Schwacke) Kosterm., display small coriaceous leaves with rounded apexes. The former is native to Japan and China (specimens in this study were collected in mountainous areas in China), while C. taubertianum is a Brazilian species, naturally distributed 


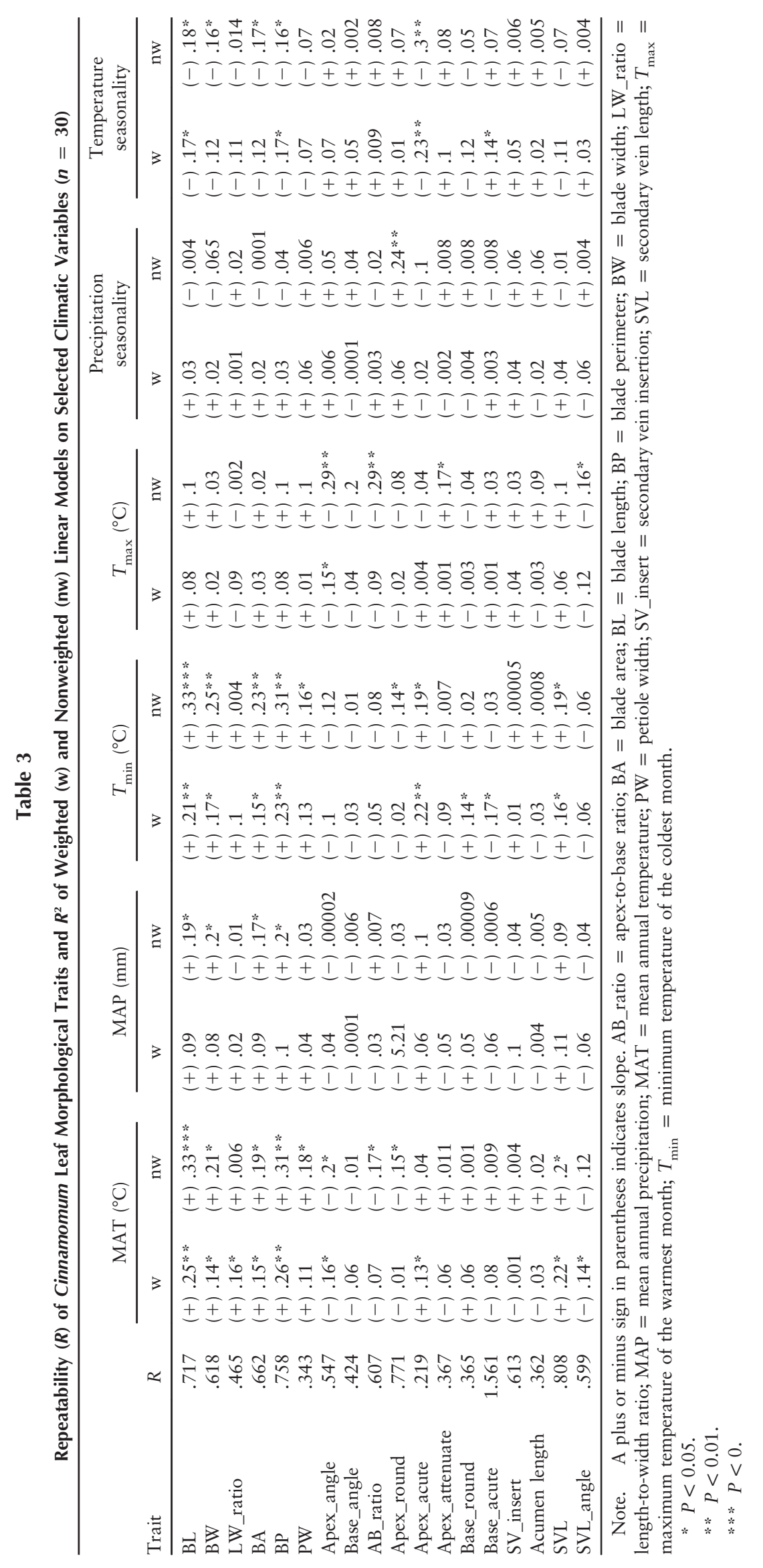



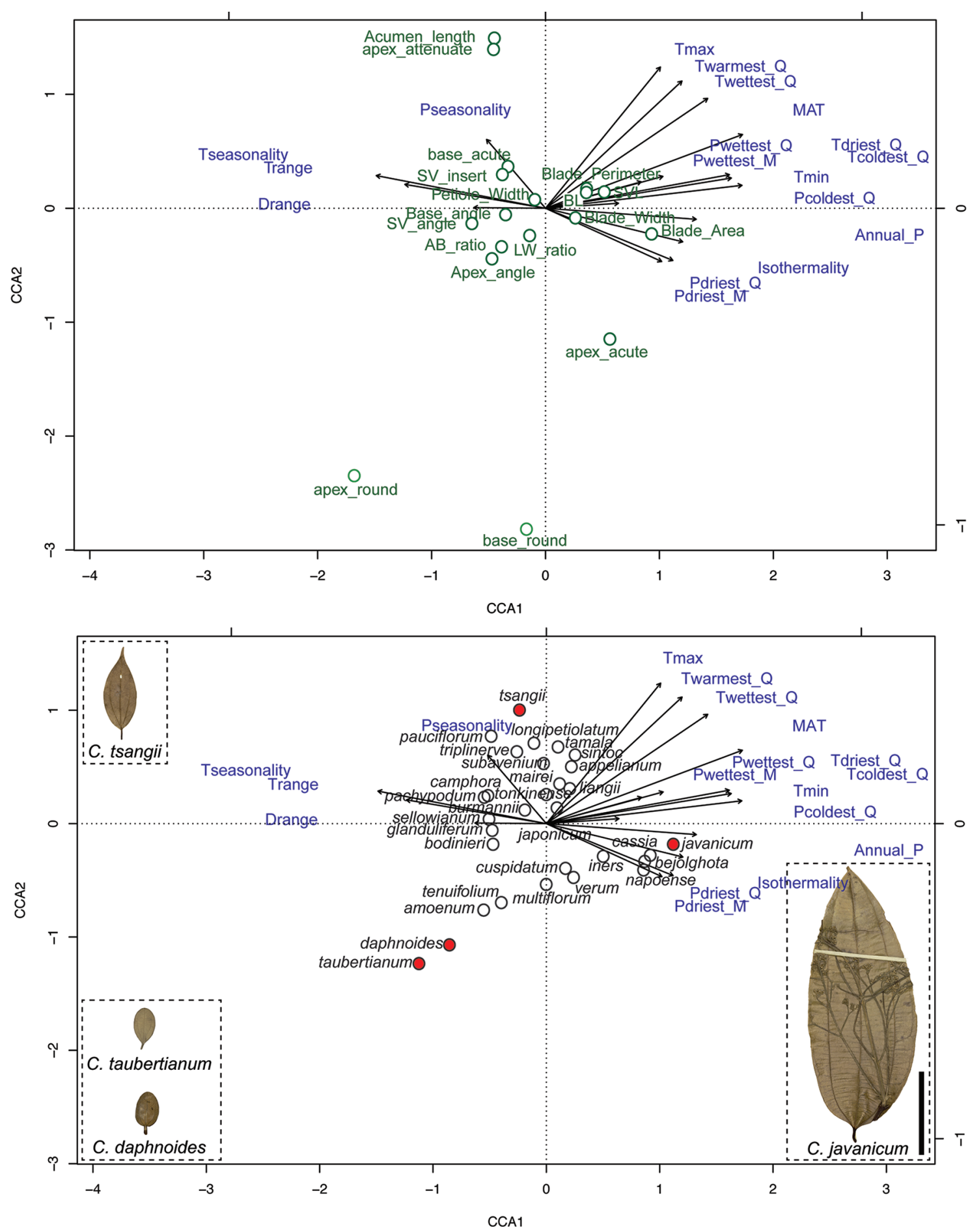

Fig. 4 Canonical correspondence analysis (CCA) of Cinnamomum morphological traits and climatic data. This analysis was conducted with mean values of morphological and climatic variables for each species. AB_ratio = apex-to-base ratio; Annual_P = annual precipitation; $\mathrm{BL}=\mathrm{blade}$ length; Drange $=$ mean diurnal range of temperature; $L$ W_ratio $=$ length-to-width ratio; MAT $=$ mean annual temperature; Pcoldest_Q $=$ precipitation of coldest quarter; Pdriest_M = precipitation of driest month; Pdriest_Q = precipitation of driest quarter; Pseasonality = precipitation seasonality; Pwettest_M = precipitation of wettest month; Pwettest_Q = precipitation of wettest quarter; SV_angle = secondary vein angle; SV_insert = secondary vein insertion; $\mathrm{SVL}=$ secondary vein length; Tcoldest_Q $=$ mean temperature of coldest quarter; Tdriest_Q $=$ mean temperature of driest quarter; Tmax $=$ maximum temperature of warmest month; $T$ min $=$ minimum temperature of coldest month; Trange $=$ temperature annual range; Tseasonality $=$ temperature seasonality; Twarmest_Q = mean temperature of warmest quarter; Twettest_Q = mean temperature of wettest quarter. Scale bar $=$ $10 \mathrm{~cm}$. Filled circles correspond to the illustrated species. 


\section{Table 4}

Canonical Correspondence Analysis (CCA) Intraset Correlation Coefficients of the Three First Ordination Axes, with Constrained Eigenvalues in Parentheses

\begin{tabular}{lr|lr|lr}
\hline & CCA1 & & CCA2 & & CCA3 \\
& $(47 \%)$ & & $(19 \%)$ & & $(7 \%)$ \\
\hline$T_{\text {range }}$ & -.507 & $P_{\text {driest_M }}$ & -.166 & MAT & .153 \\
$T_{\text {seasonality }}$ & -.417 & $P_{\text {driest_Q }}$ & -.158 & $D_{\text {range }}$ & .260 \\
$D_{\text {range }}$ & -.249 & $D_{\text {range }}$ & -.141 & Isothermality & .301 \\
$P_{\text {seasonality }}$ & -.213 & Isothermality & -.093 & $T_{\text {seasonality }}$ & -.303 \\
$P_{\text {warmest_Q }}$ & .194 & $T_{\text {range }}$ & .027 & $T_{\text {max }}$ & -.075 \\
$P_{\text {wettest_M }}$ & .254 & $T_{\text {seasonality }}$ & .039 & $T_{\text {min }}$ & .213 \\
$P_{\text {wettest_Q }}$ & .326 & Annual_P & .049 & $T_{\text {range }}$ & -.269 \\
$T_{\text {max }}$ & .331 & $T_{\text {min }}$ & .139 & $T_{\text {wettest_Q }}$ & .072 \\
$P_{\text {driest_M }}$ & .334 & $P_{\text {warmest_Q }}$ & .145 & $T_{\text {driest_Q }}$ & .241 \\
$P_{\text {driest_Q }}$ & .368 & $T_{\text {coldest_Q }}$ & .147 & $T_{\text {warmest_Q }}$ & -.092 \\
$T_{\text {warmest_Q }}$ & .396 & $P_{\text {seasonality }}$ & .172 & $T_{\text {coldest_Q }}$ & .235 \\
Isothermality & .402 & $T_{\text {driest_Q }}$ & .181 & Annual_P & .142 \\
Annual_P & .428 & $P_{\text {wettest_M }}$ & .208 & $P_{\text {wettest_M }}$ & .088 \\
$T_{\text {wettest_Q }}$ & .460 & $P_{\text {wettest_Q }}$ & .237 & $P_{\text {driest_M }}$ & .100 \\
$T_{\text {coldest_Q }}$ & .543 & MAT & .289 & $P_{\text {seasonality }}$ & .033 \\
$T_{\text {driest_Q }}$ & .545 & $T_{\text {wettest_Q }}$ & .371 & $P_{\text {wettest_Q }}$ & .127 \\
MAT & .571 & $T_{\text {max }}$ & .442 & $P_{\text {driest_Q }}$ & .104 \\
$T_{\text {min }}$ & .576 & $T_{\text {warmest_Q }}$ & .444 & $P_{\text {warmest_Q }}$ & .069 \\
\hline
\end{tabular}

Note. Annual_P $=$ annual precipitation; $D_{\text {range }}=$ mean diurnal range of temperature; MAT $=$ mean annual temperature; $P_{\text {coldest } \mathrm{Q}}=$ precipitation of coldest quarter; $P_{\text {driest } \mathrm{M}}=$ precipitation of driest month; $P_{\text {driest_Q }}=$ precipitation of driest quarter; $P_{\text {seasonality }}=$ precipitation seasonality; $\mathrm{P}_{\text {warmest_Q }}=$ precipitation of warmest quarter; $P_{\text {wettest } \mathrm{M}}=$ precipitation of wettest month; $P_{\text {wettest_Q }}=$ precipitation of wettest quarter; $T_{\text {coldest_Q }}=$ mean temperature of coldest quarter; $T_{\text {driest_Q }}=$ mean temperature of driest quarter; $T_{\max }=$ maximum temperature of warmest month; $T_{\min }=$ minimum temperature of coldest month; $T_{\text {range }}=$ temperature annual range; $T_{\text {seasonality }}=$ temperature seasonality; $T_{\text {warmest_Q }}=$ mean temperature of warmest quarter; $T_{\text {wettest_Q }}=$ mean temperature of wettest quarter.

in the Cerrado vegetation type (Lorea-Hernández 1996). Although the corresponding MATs are different $\left(10.5^{\circ}\right.$ and $17.9^{\circ} \mathrm{C}$, respectively), both species are found in climates characterized by highly seasonal temperatures and precipitation. The two species are distantly related, indicating that the C. daphnoides-C. taubertianum leaf morphologies are convergent and suggesting that these traits are climate driven. In summary, our analysis demonstrates that a number of leaf size- and shape-related traits in Cinnamomum species are influenced by climatic variables rather than by historical constraints.

Although we observed a global trend in form-climate relationship in Cinnamomum at the genus level, exceptions exist. Some species living under the same climatic constraints display very different morphologies. For instance, Cinnamomum species generally display small leaves under high MATs in association with high temperature and precipitation seasonality (e.g., C. tsangii Merr.; see fig. 4). In contrast, C. bejolghota and C. cassia (L.) J.Presl, which both live under such conditions, possess large leaves (and then occur together with C. javanicum in our analysis). Their morphology would be expected under high MAT but in association with low temperature and precipitation seasonality. Other examples are the species C. glanduliferum (Wall.) Meisn. and C. bodinieri H. Lév., both living under low MAT and high temperature seasonality. Under such conditions, Cin- namomum species generally display small leaves (e.g., the $C$. daphnoides-C. taubertianum leaf type). In contrast, C. glanduliferum and C. bodinieri possess comparatively large leaves.

These discrepancies can be explained by species-specific morphological response to climatic change (Royer et al. 2008) and/ or by abiotic parameters, such as edaphic conditions, altitude, and exposure to light, not taken into account in our survey. These results challenge the general assumption that all dicotyledon angiosperm species tend to the same leaf morphology under the same climate (Yang et al. 2015).

\section{Implications for Paleoclimatic Studies}

Physiognomic methods for paleoclimate reconstruction are based on the assumptions that similar climatic constraints lead to similar leaf morphology among and within families of woody dicotyledon angiosperms and that historical constraints on leaf morphology are negligible (Huff et al. 2003; Yang et al. 2015; Li et al. 2016a). The absence of phylogenetic signal in size and shape leaf traits of Cinnamomum and these traits' relationship with climate favor a climate-driven convergence, thus validating the use of this genus for taxon-free paleoclimatic reconstruction methods relying on such data. However, our investigation also strongly suggests that historical constraint on leaf morphology is variable among taxa, with traits presumably being driven by inheritance in some families and by climate in others. Hence, further studies using this approach in distantly related families are needed.

Cinnamomum-like fossil leaves have been found in a great number of paleofloras ranging from the Upper Cretaceous to the Miocene (e.g., Teixeira 1948; Conran and Christophel 1998; Johnson 2002; Uhl et al. 2006; Shi et al. 2014). Extant Cinnamomum leaf morphology is generally considered to be broadly representative of some Lauraceae morphotaxa observed in the fossil record, such as Laurophyllum or Daphnogene species (Kvaček 2004; Doweld 2017). In this context, our study suggests that the morphological variability observed in fossil Lauraceae could be used to give complementary information on MAT and temperature seasonality during the Cenozoic, for instance, in localities where the low number of taxa does not allow the use of traditional methods such as CLAMP.

Nevertheless, this potential use of Cinnamomum leaves, or any taxon-based methods, could be achieved only with an accurate identification of the genus in the fossil record. This might be challenging given the difficult taxonomic assignment of fossil leaves to fossil or extant Lauraceae solely on the basis of morphology and without cuticle data (Li and Christophel 2000; Shi et al. 2014; Mohamed et al. 2016). As a matter of fact, cuticle characters alone are generally insufficient for the placement of a species in a species group inside the family of extant Lauraceae (Nishida and van der Werff 2011). Therefore, in order to be fully applicable to fossil Lauraceae, our approach should also include other Lauraceae genera encompassing Cinnamomum-like leaf species that are difficult to distinguish from Cinnamomum. For instance, the genera Lindera (especially Lindera caudata) and Neocinnamomum both display triplinerved leaves. Caryodaphnopsis (Nothaphoebe), Neolitsea, and some species of Cryptocarya are characterized by triplinerved leaves and secondary veins.

However, despite numerous phylogeny works focused on several Lauraceae genera and global phylogenies, the relationships are still unresolved and mainly show that some of the genera are para- or polyphyletic. This is the case for Actinodaphne, 
Cinnamomum, Lindera, Litsea, Neolitsea, and Persea (Rohwer 2000; Chanderbali et al. 2001; J. Li et al. 2004; Rohwer and Rudolph 2005; Z. Li et al. 2006; L. Li et al. 2007, 2011; Fijridiyanto and Murakami 2009; Rohwer et al. 2009, 2014; Huang et al. 2016; Rohde et al. 2017; Cruz-Maya and Barrientos-Priego 2018; Zhao et al. 2018). Consequently, these genera as traditionally understood are not efficient for assigning fossil leaves to a particular taxon. Hence species-based phylogenies providing revised relationships, such as the one used as a phylogenetic framework here, appear to be more efficient for inferring adaptation interpretation than former definitions and limits of the genera are.

Numerous fossil species have been described in Europe and attributed to Cinnamomum, mainly on the basis of secondary venation pattern (Saporta 1863, 1867; Unger 1867; Fritel 1905a, $1905 b$; Laurent 1912), and thus, they would need consequent taxonomic revision. Cinnamomoid-type leaves (with three basal veins) without accurate cuticle information are generally assigned to the genus Daphnogene by paleobotanists (Kvaček 1971). As stated above, this morphological trait is not exclusive to Cinnamomum at present. Hence, Daphnogene is considered an artificial group (Kvaček 1971) and is probably a mix of different fossil (and extant?) genera. However, the use of this group is still useful for avoiding confusions and misplacement of fossil triplinerved leaves in extant genera, as was done in the past.

Given the above, a global analysis of the leaf morphology variation in the extant Lauraceae family would allow the reassessment of the fossil record in order to extract climatic signals from leaf morphology. Hence, the next step should be the use of a global phylogeny to develop this approach at the family level and to apply these results to Cinnamomum-like fossil leaves in order to optimize the accuracy of the paleoclimatic interpretation.

In this endeavor, our study demonstrates that digitized herbarium collections represent an interesting data source for future studies in this field.

\section{Conclusion}

To our knowledge, this study is the first to document the relationship among Cinnamomum leaf architecture, phylogeny, and climatic parameters. According to our analysis, Cinnamomum leaf architecture is influenced by a combination of both evolutionary history and climatic selective pressure, as (1) a number of leaf size- and shape-related traits in Cinnamomum species are influenced by climatic variables and (2) traits relating to venation patterns are influenced by historical constraints.

As observed in community-level studies, size-related traits and apex type in Cinnamomum are correlated with MAT but also with temperature seasonality. The absence of phylogenetic signal in size and shape leaf traits in Cinnamomum favors the use of this genus for physiognomic paleoclimatic reconstruction methods. Additionally, we suggest that the genus, when correctly identified, could be used as a qualitative proxy in small paleontological samples.

The absence of phylogenetic signal in size- and shape-related traits contrasts with earlier studies of distantly related taxa and confirms that historical constraints on leaf morphology are variable among families. Consequently, our study emphasizes the importance of further testing the influence of phylogeny on leaf morphology at low and high taxonomic levels, including intraspecific studies. Additionally, it underlines the importance of a well-known phylogenetic framework and appropriate sampling for such investigations. A more accurate knowledge of the potentially different form-climate relationships observed at these levels would certainly contribute to refined paleoclimatic reconstruction methods.

\section{Acknowledgments}

We wish to thank the ReColNat infrastructure (e-ReColNat [ANR-11-INBS-0004]) and especially the Herbonautes project for their valuable help in gathering geolocation data from digitized herbarium specimens. We also warmly thank O. Bethoux for fruitful discussions and for his help with the writing of the manuscript. Finally, we thank Thomas Denk and an anonymous reviewer for their thoughtful comments and corrections on the first version of the manuscript.

\section{Literature Cited}

Andrey P, Y Maurin 2005 Free-D: an integrated environment for three-dimensional reconstruction from serial sections. J Neurosci Methods 145:233-244.

Bailey IW, EW Sinnott 1915 A botanical index of Cretaceous and Tertiary climates. Science 41:831-834.

1916 The climatic distribution of certain types of angiosperm leaves. Am J Bot 3:24-39.

Biot E, M Cortizo, J Burguet, A Kiss, M Oughou, A Maugarny-Calès, B Gonçalves, et al 2016 Multiscale quantification of morphodynamics: MorphoLeaf software for 2D shape analysis. Development 143:34173428.

Blomberg SP, T Garland Jr, AR Ives 2003 Testing for phylogenetic signal in comparative data: behavioral traits are more labile. Evolution 57:717-745.

Burnham RJ, GS Tonkovich 2011 Climate, leaves, and the legacy of two giants. New Phytol 190:514-517.
Chanderbali AS, H van der Werff, SS Renner 2001 Phylogeny and historical biogeography of Lauraceae: evidence from the chloroplast and nuclear genomes. Ann Mo Bot Gard 88:104-134.

Conran JG, DC Christophel 1998 A new species of triplinerved Laurophyllum from the Eocene of Nerriga, New South Wales. Alcheringa $22: 343-348$

Cruz-Maya ME, AF Barrientos-Priego 2018 Phylogenetic analysis of some members of the subgenus Persea (Persea, Lauraceae). Rev Chapingo Ser Hortic 24:133-150.

Dolph GE, DL Dilcher 1980a Variation in leaf size with respect to climate in Costa Rica. Biotropica 12:91-99.

$1980 b$ Variation in leaf size with respect to climate in the tropics of the Western Hemisphere. Bull Torrey Bot Club 107:154-162.

Doweld AB 2017 New names in Cinnamomoides, Cinnamomum and Neolitsea (Lauraceae), and Pterospermum (Malvaceae), fossil and living. Phytotaxa 326:189-201. 
Ellis B, DC Daly, LJ Hickey, KR Johnson, JD Mitchell, P Wilf, SL Wing 2009 Manual of leaf architecture. Vol 190. Cornell University Press, Ithaca, NY.

Farji-Brener AG, O Valverde, L Paolini, M de los Angeles La Torre, E Quintero, E Bonaccorso, L Arnedo, R Villalobos 2002 Acumen function in leaves and its vertical distribution in a tropical rain forest of Costa Rica. Rev Biol Trop 50:561-567.

Fijridiyanto IA, N Murakami 2009 Phylogeny of Litsea and related genera (Laureae-Lauraceae) based on analysis of rpb2 gene sequences. J Plant Res 122:283-298.

Fritel HP 1905a Les Cinnamomum fossiles de France. Naturaliste 438:125-129.

— 1905b Plante fossile nouvelle des schistes lignitigères de Ménat. Naturaliste 430:31-32.

Garamszegi LZ 2014 Uncertainties due to within-species variation in comparative studies: measurement errors and statistical weights. Pages 157-199 in LZ Garamszegi, ed. Modern phylogenetic comparative methods and their application in evolutionary biology. Springer, New York.

Glade-Vargas N, LF Hinojosa, M Leppe 2018 Evolution of climatic related leaf traits in the family Nothofagaceae. Front Plant Sci 9: 1073.

Greenwood DR, P Wilf, SL Wing, DC Christophel 2004 Paleotemperature estimation using leaf-margin analysis: is Australia different? Palaios 19:129-142.

Gregory-Wodzicki KM 2000 Relationships between leaf morphology and climate, Bolivia: implications for estimating paleoclimate from fossil floras. Paleobiology 26:668-688.

Hansen TF, K Bartoszek 2012 Interpreting the evolutionary regression: the interplay between observational and biological errors in phylogenetic comparative studies. Syst Biol 61:413-425.

Harper DGC 1994 Some comments on the repeatability of measurements. Ringing Migr 15:84-90.

Herman AB, RA Spicer 1997 New quantitative palaeoclimate data for the Late Cretaceous Arctic: evidence for a warm polar ocean. Palaeogeogr Palaeoclimatol Palaeoecol 128:227-251.

Hijmans RJ, SE Cameron, JL Parra, PG Jones, A Jarvis 2005 Very high resolution interpolated climate surfaces for global land areas. Int J Climatol 25:1965-1978.

Hinojosa LF, F Pérez, A Gaxiola, I Sandoval 2011 Historical and phylogenetic constraints on the incidence of entire leaf margins: insights from a new South American model. Glob Ecol Biogeogr 20:380-390.

Ho K-Y, T-Y Hung 2011 Cladistic relationships within the genus Cinnamomum (Lauraceae) in Taiwan based on analysis of leaf morphology and inter-simple sequence repeat (ISSR) and internal transcribed spacer (ITS) molecular markers. Afr J Biotechnol 10:4802-4815.

Holden AM 1982 Fossil Lauraceae and Proteaceae from the Longford Formation, Murchison, New Zealand. J R Soc NZ 12:79-90.

Huang J-F, L Li, H van der Werff, H-W Li, JG Rohwer, DM Crayn, H-H Meng, M van der Merwe, JG Conran, J Li 2016 Origins and evolution of cinnamon and camphor: a phylogenetic and historical biogeographical analysis of the Cinnamomum group (Lauraceae). Mol Phylogenet Evol 96:33-44.

Huff PM, P Wilf, EJ Azumah 2003 Digital future for paleoclimate estimation from fossil leaves: preliminary results. Palaios 18:266-274.

Ives AR, PE Midford, T Garland Jr 2007 Within-species variation and measurement error in phylogenetic comparative methods. Syst Biol 56:252-270.

Johnson KR 2002 Megaflora of the Hell Creek and lower Fort Union Formations in the western Dakotas: vegetational response to climate change, the Cretaceous-Tertiary boundary event, and rapid marine transgression. GSA Special Paper 361. GSA, Boulder, CO.

Kennedy EM, RA Spicer, PM Rees 2002 Quantitative palaeoclimate estimates from Late Cretaceous and Paleocene leaf floras in the northwest of the South Island, New Zealand. Palaeogeogr Palaeoclimatol Palaeoecol 184:321-345.
Khan MA, S Bera 2014 New lauraceous species from the Siwalik forest of Arunachal Pradesh, eastern Himalaya, and their palaeoclimatic and palaeogeographic implications. Turk J Bot 38:453-464.

Kowalski EA 2002 Mean annual temperature estimation based on leaf morphology: a test from tropical South America. Palaeogeogr Palaeoclimatol Palaeoecol 188:141-165.

Kvaček Z 1971 Fossil Lauraceae in the stratigraphy of the NorthBohemian Tertiary. Sb Geol Věd Paleontol 13:47-86.

2004 Revisions to the Early Oligocene flora of Flörsheim (Mainz Basin, Germany) based on epidermal anatomy. Senckenb Lethaea 84:173.

Laurent L 1912 Flore fossile des schistes de Menat (Puy-de-Dôme). Annales du Musée d'Histoire Naturelle de Marseille, Mouillot, Marseille.

Le Bras G, M Pignal, ML Jeanson, S Muller, C Aupic, B Carré, G Flament, et al 2017 The French Muséum National d'Histoire Naturelle vascular plant herbarium collection dataset. Sci Data 4:170016.

Li J, DC Christophel 2000 Systematic relationships within the Litsea complex (Lauraceae): a cladistic analysis on the basis of morphological and leaf cuticle data. Aust Syst Bot 13:1-13.

Li J, DC Christophel, JG Conran, HW Li 2004 Phylogenetic relationships within the "core" Laureae (Litsea complex, Lauraceae) inferred from sequences of the chloroplast gene matK and nuclear ribosomal DNA ITS regions. Plant Syst Evol 246:19-34.

Li L, J Li, JG Conran, XW Li, HW Li 2007 Phylogeny of Neolitsea (Lauraceae) inferred from Bayesian analysis of nrDNA ITS and ETS sequences. Plant Syst Evol 269:203-221.

Li L, J Li, JG Rohwer, H van der Werff, Z-H Wang, H-W Li 2011 Molecular phylogenetic analysis of the Persea group (Lauraceae) and its biogeographic implications on the evolution of tropical and subtropical Amphi-Pacific disjunctions. Am J Bot 98:1520-1536.

Li S-F, FMB Jacques, RA Spicer, T Su, TEV Spicer, J Yang, Z-K Zhou 2016a Artificial neural networks reveal a high-resolution climatic signal in leaf physiognomy. Palaeogeogr Palaeoclimatol Palaeoecol 442:111.

Li Y, Z Wang, X Xu, W Han, Q Wang, D Zou $2016 b$ Leaf margin analysis of Chinese woody plants and the constraints on its application to palaeoclimatic reconstruction. Glob Ecol Biogeogr 25:1401-1415.

Li Z-M, J Li, X Li 2006 Polyphyly of the genus Actinodaphne (Lauraceae) inferred from the analyses of nrDNA ITS and ETS sequences. Acta Phytotaxon Sin 44:272-285.

Little SA, SW Kembel, P Wilf 2010 Paleotemperature proxies from leaf fossils reinterpreted in light of evolutionary history. PLoS ONE 5:e15161.

Lorea-Hernández FG 1996 A systematic revision of the Neotropical species of Cinnamomum Schaeffer (Lauraceae). PhD diss. University of Missouri, St. Louis.

Losos JB 2008 Phylogenetic niche conservatism, phylogenetic signal and the relationship between phylogenetic relatedness and ecological similarity among species. Ecol Lett 11:995-1007.

Maddison WP, DR Maddison 2017 Mesquite: a modular system for evolutionary analysis. Version 3.2. Mesquite. http://www.mesquite project.org.

Milla R, PB Reich 2011 Multi-trait interactions, not phylogeny, finetune leaf size reduction with increasing altitude. Ann Bot 107:455-465.

Mohamed A-SH, W Ahmed, SS Rabia, MM Mourad 2016 Implications of morphology and molecular criteria in taxonomy of Lauraceae Juss. Egypt J Exp Biol Bot 12:45-52.

Moles AT, SE Perkins, SW Laffan, H Flores-Moreno, M Awasthy, ML Tindall, L Sack, et al 2014 Which is a better predictor of plant traits: temperature or precipitation? J Veg Sci 25:1167-1180.

Münkemüller T, S Lavergne, B Bzeznik, S Dray, T Jombart, K Schiffers, W Thuiller 2012 How to measure and test phylogenetic signal. Methods Ecol Evol 3:743-756.

Nishida S, H van der Werff 2011 An evaluation of classification by cuticular characters of the Lauraceae: a comparison to molecular phylogeny. Ann Mo Bot Gard 98:348-357. 
Peppe DJ, A Baumgartner, A Flynn, B Blonder 2018 Reconstructing paleoclimate and paleoecology using fossil leaves. Pages 289-317 in DA Croft, D Su, SW Simpson, eds. Methods in paleoecology. Springer, Cham, Switzerland.

Peppe DJ, DL Royer, B Cariglino, SY Oliver, S Newman, E Leight, G Enikolopov, et al 2011 Sensitivity of leaf size and shape to climate: global patterns and paleoclimatic applications. New Phytol 190:724-739.

R Core Team 2017 R: a language and environment for statistical computing. R Foundation for Statistical Computing, Vienna.

Revell LJ 2012 Phytools: an R package for phylogenetic comparative biology (and other things). Methods Ecol Evol 3:217-223.

Rohde R, B Rudolph, K Ruthe, FG Lorea-Hernández, PLR De Moraes, J Li, JG Rohwer 2017 Neither Phoebe nor Cinnamomum: the tetrasporangiate species of Aiouea (Lauraceae). Taxon 66:1085-1111.

Rohwer JG 2000 Toward a phylogenetic classification of the Lauraceae: evidence from matK sequences. Syst Bot 25:60-71.

Rohwer JG, PLR De Moraes, B Rudolph, H van der Werff 2014 A phylogenetic analysis of the Cryptocarya group (Lauraceae), and relationships of Dablgrenodendron, Sinopora, Triadodaphne, and Yasunia. Phytotaxa 158:111-132.

Rohwer JG, J Li, B Rudolph, SA Schmidt, H van der Werff, HW Li 2009 Is Persea (Lauraceae) monophyletic? evidence from nuclear ribosomal ITS sequences. Taxon 58:1153-1167.

Rohwer JG, B Rudolph 2005 Jumping genera: the phylogenetic positions of Cassytha, Hypodaphnis, and Neocinnamomum (Lauraceae) based on different analyses of trnK intron sequences. Ann Mo Bot Gard 92:153-178.

Royer DL 2012 Leaf shape responds to temperature but not $\mathrm{CO}_{2}$ in Acer rubrum. PLoS ONE 7:e49559.

Royer DL, JC McElwain, JM Adams, P Wilf 2008 Sensitivity of leaf size and shape to climate within Acer rubrum and Quercus kelloggii. New Phytol 179:808-817.

Sack L, C Scoffoni, AD McKown, K Frole, M Rawls, JC Havran, H Tran, T Tran 2012 Developmentally based scaling of leaf venation architecture explains global ecological patterns. Nat Commun 3:837.

Saporta G 1863 Etude sur la végétation du sud-est de la France à l'époque tertiaire. I. Masson, Paris.

— 1867 Etude sur la végétation du sud-est de la France à l'époque tertiaire. III. Masson, Paris.

Schmerler SB, WL Clement, JM Beaulieu, DS Chatelet, L Sack, MJ Donoghue, EJ Edwards 2012 Evolution of leaf form correlates with tropical-temperate transitions in Viburnum (Adoxaceae). Proc R Soc Biol Sci 279:3905-3913.

Schneider CA, WS Rasband, KW Eliceiri 2012 NIH Image to Image J: 25 years of image analysis. Nat Methods 9:671.

Schnell R 1987 La flore et la végétation de l'Amérique tropicale. Vol I. Masson, Paris.

Shi GL, ZM Xie, HM Li 2014 High diversity of Lauraceae from the Oligocene of Ningming, South China. Palaeoworld 23:336-356.

Sokal RR, FJ Rohlf 1995 Biometry. 3rd ed. Freeman, New York.
Stoffel MA, S Nakagawa, H Schielzeth 2017 rptR: repeatability estimation and variance decomposition by generalized linear mixedeffects models. Methods Ecol Evol 8:1639-1644.

Su T, Y-W Xing, Y-SC Liu, FMB Jacques, W-Y Chen, Y-J Huang, Z-K Zhou 2010 Leaf margin analysis: a new equation from humid to mesic forests in China. Palaios 25:234-238.

Taylor DW 1988 Eocene floral evidence of Lauraceae: corroboration of the North American megafossil record. Am J Bot 75:948-957.

Teixeira C 1948 Flora mesozóica portuguesa. Direcçāo Geral de Minas e Serviços Geológicos. Serviços Geológicos de Portugal, Lisbon.

Teodoridis V, P Mazouch, RA Spicer, D Uhl 2011 Refining CLAMP: investigations towards improving the Climate Leaf Analysis Multivariate Program. Palaeogeogr Palaeoclimatol Palaeoecol 299:3948.

Ter Braak CJ 1986 Canonical correspondence analysis: a new eigenvector technique for multivariate direct gradient analysis. Ecology 67:1167-1179.

Traiser C, S Klotz, D Uhl, V Mosbrugger 2005 Environmental signals from leaves: a physiognomic analysis of European vegetation. New Phytol 166:465-484.

Uhl D 2014 Variability of selected leaf traits in European beech (Fagus sylvatica) in relation to climatic factors: some implications for palaeoenvironmental studies. Phytol Balc 20:145-153.

Uhl D, AA Bruch, C Traiser, S Klotz 2006 Palaeoclimate estimates for the Middle Miocene Schrotzburg flora (S Germany): a multimethod approach. Int J Earth Sci 95:1071-1085.

Unger F 1867 Die fossile flora von Kumi auf der Insel Euboea. KaiserlichKöniglichen, Vienna.

Wilf P, SL Wing, DR Greenwood, CL Greenwood 1998 Using fossil leaves as paleoprecipitation indicators: an Eocene example. Geology 26:203-206.

Wolfe JA 1993 A method of obtaining climatic parameters from leaf assemblages. USGS Bulletin 2040. USGS, Washington, DC.

1995 Paleoclimatic estimates from Tertiary leaf assemblages. Annu Rev Earth Planet Sci 23:119-142.

Wright IJ, N Dong, V Maire, IC Prentice, M Westoby, S Díaz, RV Gallagher, et al 2017 Global climatic drivers of leaf size. Science 357: 917-921.

Wuu-Kuang S 2011 Taxonomic revision of Cinnamomum (Lauraceae) in Borneo. Blumea 56:241-264.

Yang J, RA Spicer, TEV Spicer, NC Arens, FMB Jacques, T Su, EM Kennedy, et al 2015 Leaf form-climate relationships on the global stage: an ensemble of characters. Glob Ecol Biogeogr 24:1113-1125.

Yang J, RA Spicer, TEV Spicer, C-S Li 2011 "CLAMP Online": a new web-based palaeoclimate tool and its application to the terrestrial Paleogene and Neogene of North America. Palaeobiodivers Palaeoenviron 91:163-183.

Zhao ML, Y Song, J Ni, X Yao, YH Tan, ZF Xu 2018 Comparative chloroplast genomics and phylogenetics of nine Lindera species (Lauraceae). Sci Rep 8:8844. 